\title{
Elevation of anti-elastin antibody in patients with asthma
}

\author{
Shingo Tokita, ${ }^{1}$ Kumiya Sugiyama,,${ }^{1,2}$ Tomoshige Wakayama, ${ }^{1}$ Hajime Arifuku, ${ }^{1}$ Naotatsu Otsuji, ${ }^{1}$ Kei Sugitate,${ }^{1}$ \\ Takayoshi Owada, ${ }^{1}$ Kenya Koyama, ${ }^{1}$ Hirokuni Hirata, ${ }^{1}$ Masafumi Arima, ${ }^{4}$ Yoshihiko Ueda,${ }^{3}$ Yasutsugu Fukushima ${ }^{1}$
}

\begin{abstract}
Background: It is often difficult to differentiate between asthma and chronic obstructive pulmonary disease (COPD), and useful biomarkers are needed for accurate diagnosis.

Objective: We evaluated anti-elastin antibody to identify useful biomarkers for differentiating between a diagnosis of asthma and COPD.

Method: Patients with asthma (male to female ratio $=10 / 13$; mean age, 67.3 years), COPD (16/0; 74.8 years) and controls $(8 / 4 ; 72.3$ years) were enrolled. Samples from sputum and serum were collected and levels of anti-elastin Ab were measured.

Results: The levels of anti-elastin Ab in sputum were significantly higher in asthma $(11.4 \pm 7.16 \mu \mathrm{g} / \mathrm{mL})$ than in COPD $(5.82 \pm 5.16 \mu \mathrm{g} / \mathrm{mL} ; P<0.01)$, and serum levels in asthma $(67.4 \pm 29.7 \mu \mathrm{g} / \mathrm{mL})$ were also significantly higher than in COPD or controls $(45.0 \pm 12.8 \mu \mathrm{g} / \mathrm{mL} ; P<0.05,38.6 \pm 10.4 \mu \mathrm{g} / \mathrm{mL} ; P<0.01$, respectively). Anti-elastin Ab in sputum showed a positive correlation with smoking in asthma $\left(\mathrm{r}^{2}=0.218, P<0.05\right)$. However, no significant differences were observed in the levels of anti-elastin $\mathrm{Ab}$ and eosinophils, asthma phenotypes, inhaled corticosteroids, or severity in patients with asthma. Elastin was strongly expressed under the airway basement membrane in asthma compared with COPD or the healthy control.
\end{abstract}

Conclusions: Anti-elastin $\mathrm{Ab}$ in sputum could be a useful biomarker for COPD and asthma in ever-smokers. In asth$\mathrm{ma}$, anti-elastin $\mathrm{Ab}$ was recruited to the airways by both airway allergic inflammation and smoking, and it may contribute to the progression of airway remodeling via autoimmune inflammation, but not emphysema, in COPD.

Key words: anti-elastin antibody; airway remodeling; asthma; COPD; smoking

From:

${ }^{1}$ Department of Respiratory Medicine and Clinical Immunology, Dokkyo Medical University, Saitama Medical Center, Saitama, Japan

${ }^{2}$ National Hospital Organization, Utsunomiya National Hospital,

Tochigi, Japan

${ }^{3}$ Department of Pathology, Dokkyo Medical University,

Saitama Medical Center, Saitama, Japan

${ }^{4}$ Department of Rheumatology, Dokkyo Medical University,

Tochigi, Japan

\section{Introduction}

It is often difficult to differentiate between asthma and chronic obstructive pulmonary disease (COPD) because some symptoms are very similar. Useful biomarkers are needed for doctors to obtain an accurate diagnosis. COPD is characterized by chronic neutrophilic inflammation induced by smoking, which leads to emphysema and airway obstruction. ${ }^{1}$ In one hypothesis on the mechanism of COPD, autoimmune disease can cause emphysema. ${ }^{2,3}$ High levels of anti-elastin

\section{Corresponding author:}

Kumiya Sugiyama

Department of Respiratory Medicine and Clinical Immunology,

Dokkyo Medical University, Saitama Medical Center

2-1-50 Minami-Koshigaya, Koshigaya, Saitama 343-8555, Japan

E-mail: sugiyama@dokkyomed.ac.jp

antibody $(\mathrm{Ab})$ as an autoantibody have been detected in the plasma of patients with severe emphysema. ${ }^{4}$ However, another publication has reported lower levels of anti-elastin $\mathrm{Ab}$ in patients with COPD and that smoke exposure suppressed the production of anti-elastin $\mathrm{Ab} .{ }^{5}$ Therefore, the relationship between anti-elastin $\mathrm{Ab}$ and COPD is not yet clear. In addition, few studies have reported on the relationship between asthma and anti-elastin $\mathrm{Ab}$. 
There are no reports on anti-elastin $\mathrm{Ab}$ in patients with asthma. To identify useful biomarkers for the diagnosis of asthma and COPD, we evaluated anti-elastin $\mathrm{Ab}$ in sputum and serum in patients with these conditions.

\section{Methods \\ Study design}

Patients with stable asthma or COPD who visited our hospital regularly were enrolled. Asthma and COPD were diagnosed according to the guidelines of the Global Initiative for Asthma (GINA) or the Global Initiative for Chronic Obstructive Lung Disease (GOLD). ${ }^{1,6}$ We collected patients' sputum and serum and measured the levels of anti-elastin Ab. Patients with asthma-COPD overlap were excluded from this study because the aim was to differentiate between asthma and COPD.

This study was performed prospectively and was approved by the Ethics Committee of Dokkyo Medical University Saitama Medical Center (No. 1430 and 19109). Written informed consent was obtained from all patients. Human lung tissues, which were obtained through operations or autopsy, were used according to the guidelines of the Ethics Committee of Dokkyo Medical University Saitama Medical Center.

\section{Participants}

The enrolled patients included 23 with asthma, 16 with COPD, and 12 as controls without asthma and COPD. The overall mean age was 70.8 years (asthma, 67.3 years; COPD, 74.8 years; controls, 72.3 years) and the male/female ratio was 34/17 (asthma, 10/13; COPD, 16/0; control, 8/4). The baseline characteristics of the patients are shown in Table $\mathbf{1}$.

In accordance with the 2020 GINA guidelines, the patients were divided into 5 asthma phenotypes: allergic asthma, non-allergic asthma, adult-onset asthma, asthma with persistent airflow limitation and asthma with obesity. ${ }^{7}$ The allergic asthma group consisted of 9 patients who had an immunoglobulin E (IgE) level of $173 \mathrm{IU} / \mathrm{mL}$ or higher, which is widely used as a cut-off value in Japan. The non-allergic asthma group consisted of 8 patients with an IgE level of less than $173 \mathrm{IU} / \mathrm{mL}$. All patients had adult-onset asthma. The asthma with persistent airflow limitation group consisted of 6 patients who had $\% \mathrm{FEV}_{1}$ (forced expiratory volume in $1 \mathrm{~s}$ ) of less than $80 \%$ of the predicted value. The asthma with obesity group consisted of 5 patients with a body mass index (BMI) greater than 25. We also evaluated comorbidities of allergic diseases or arteriosclerosis. Allergic rhinitis, atopic dermatitis, hypertension, diabetes, and dyslipidemia were present in $9,0,6,5$, and 7 patients, respectively. In evaluation of differences in inhaled corticosteroids (ICSs), fluticasone propionate was used as the standard. Thus, the dose of other ICSs was calculated relative to the dose of fluticasone propionate. ${ }^{8}$

Extracted lung specimens from lung cancer cases were used for elastin immunohistochemistry in patients with asthma and COPD. One patient with asthma was a 62-year-old man at Step III severity level. ${ }^{6}$ The other patient with COPD was a 74-year-old man at Gold II severity level. ${ }^{1}$ A lung specimen from a 31-year-old man who died after a brain infarction and had no smoking history was used as a healthy control.
Table 1. Participant characteristics at baseline.

\begin{tabular}{|c|c|c|c|}
\hline & Asthma & COPD & Controls \\
\hline Patient (n) & 23 & 16 & 12 \\
\hline Mean age (years) * & $67.3 \pm 7.99$ & $74.8 \pm 8.01$ & $72.3 \pm 7.78$ \\
\hline Male/Female $e^{\star *}$ & $10 / 13$ & $16 / 0$ & $8 / 4$ \\
\hline Duration (years) & $10.4 \pm 9.20$ & $7.27 \pm 6.13$ & \\
\hline Smoking ${ }^{* *}$ & 11 & 16 & 8 \\
\hline \multicolumn{4}{|l|}{ Severity } \\
\hline Step/Gold I & 3 & 1 & \\
\hline Step/Gold II & 4 & 1 & \\
\hline Step/Gold III & 10 & 11 & \\
\hline Step/Gold IV & 6 & 3 & \\
\hline FeNO (ppb) & $47.9 \pm 53.8$ & $\mathrm{~N} / \mathrm{A}$ & N/A \\
\hline Brinkman Index ${ }^{*}$ & $491.8 \pm 269.3$ & $1122.7 \pm 591.0$ & $803.0 \pm 407.1$ \\
\hline Serum IgE (IU/mL) & $389.5 \pm 723.4$ & $126.3 \pm 103.6$ & N/A \\
\hline $\begin{array}{l}\text { Blood eosinophils } \\
(\%)\end{array}$ & $6.47 \pm 7.00$ & $2.68 \pm 1.64$ & $2.43 \pm 1.88$ \\
\hline \multicolumn{4}{|l|}{ Pulmonary function } \\
\hline$\% \mathrm{FVC}^{*}$ & $98.7 \pm 14.1$ & $87.1 \pm 17.9$ & $91.1 \pm 18.0$ \\
\hline$\% \mathrm{FEV}_{1}^{* *}$ & $88.2 \pm 21.4$ & $64.9 \pm 20.9$ & $99.6 \pm 10.4$ \\
\hline $\mathrm{FEV}_{1 \%}{ }^{* *}$ & $66.5 \pm 13.5$ & $51.5 \pm 12.0$ & $73.9 \pm 14.4$ \\
\hline$\% \mathrm{~V}_{50}^{* *}$ & $41.4 \pm 24.0$ & $19.2 \pm 14.9$ & $60.5 \pm 46.8$ \\
\hline$\% \mathrm{~V}_{25}$ & $28.3 \pm 16.7$ & $21.6 \pm 13.5$ & $53.6 \pm 59.9$ \\
\hline
\end{tabular}

Values are the mean \pm standard deviation; ${ }^{\star} P<0.05 ;{ }^{* *} P<0.01$ between asthma and COPD.

$\% \mathrm{FVC}$, forced vital capacity (\% of predicted); $\% \mathrm{FEV}_{1}$, forced expiratory volume in $1 \mathrm{~s}$ (\% of predicted); $\mathrm{FEV}_{1 \%}$, forced expiratory volume in $1 \mathrm{~s} \%$, meaning $\mathrm{FEV} / \mathrm{FVC} \times 100 \% ; \% \mathrm{~V}_{50}$, maximum expiratory flow at $50 \%$ of the forced vital capacity ( $\%$ of predicted); $\% \mathrm{~V}_{25}$, maximum expiratory flow at $25 \%$ of the forced vital capacity ( $\%$ of predicted).

\section{Collection of blood and induction of sputum samples}

Peripheral whole venous blood was collected, and serum was prepared by centrifugation and stored at $-80^{\circ} \mathrm{C}$ until the analysis.

Sputum was induced by inhalation of physiological saline solution (Otsuka Pharmaceutical Co., Ltd., Tokyo, Japan). Sputum was smeared onto slides and treated with Giemsa staining. The numbers and percentages of cell differences were counted on each slide. In the neutrophil count, less than 100 cells per field was represented by '-,' 500 cells per field by '+', 1,000 cells per field by '++', and over 1,000 cells per field by ' +++ ' via $100 \times$ magnification. In the eosinophil count, no cells per field was represented by '-,' 100 cells per field by '+,' 500 cells per field by ' ++ ,' and over 500 cells per field by ' +++ ' via $100 \times$ magnification. Sputum was prepared by centrifugation for $30 \mathrm{~min}$ at $15,000 \mathrm{rpm}$ at $4^{\circ} \mathrm{C}$ and supernatants were frozen at $-80^{\circ} \mathrm{C}$ for the biological assays. 
Enzyme-linked immunosorbent assay (ELISA) for anti-elastin $A b$

The anti-human elastin $\mathrm{Ab}$ quantification assay was performed using a modified ELISA protocol. ${ }^{3}$ Briefly, human lung elastin QP45 was purchased from Elastin Products Company Inc. (Owensville, MO), dissolved, and used to coat ELISA plates. After incubation and washing, serum or sputum samples were diluted and incubated. After further washing, biotinylated chicken anti-human IgG H\&L (ab112452, Abcam, Cambridge, UK) was added and the samples were incubated. Plates were washed again, HRP-streptavidin (ab7403, Abcam) was added, and the samples were incubated. After a final wash, o-phenylenediamine dihydrochloride (Wako Pure Chemical Industries, Ltd. Osaka, Japan) was added and the optical density of the individual wells was determined. Rabbit anti-elastin Ab (ab23747, Abcam) was used for the standard curve.

\section{Elastin immunohistochemistry}

Elastin immunohistochemistry was performed to evaluate the expression of elastin in human lung tissues. Briefly, mouse anti-elastin antibody (ab77804, Abcam) was incubated with human lung tissues for $60 \mathrm{~min}$ after blocking. Tissues were washed and subjected to DAKO Envision FLEX (Agilent Technologies, Inc. Santa Clara, CA). After the tissues were washed, DAB was used as the chromogen. Then, the tissues were washed again and stained by Mayer's hemalum solution.

\section{Statistical analysis}

All statistical analyses were performed using Microsoft ${ }^{\circledR}$ Excel $^{\circledR} 2016$ MSO (Microsoft Corp., Redmond, WA) and $\mathrm{JMP}^{\circledR}$ Pro version 11.0.0 (SAS Institute, Cary, NC) statistical software. Differences between two independent samples were examined by chi-squared and Mann-Whitney $U$ tests. The relationships between two parameters were examined by correlation coefficients and regression analysis. A $P$ value of $<0.05$ was considered statistically significant. The results are expressed as means \pm standard deviation (SD).

A

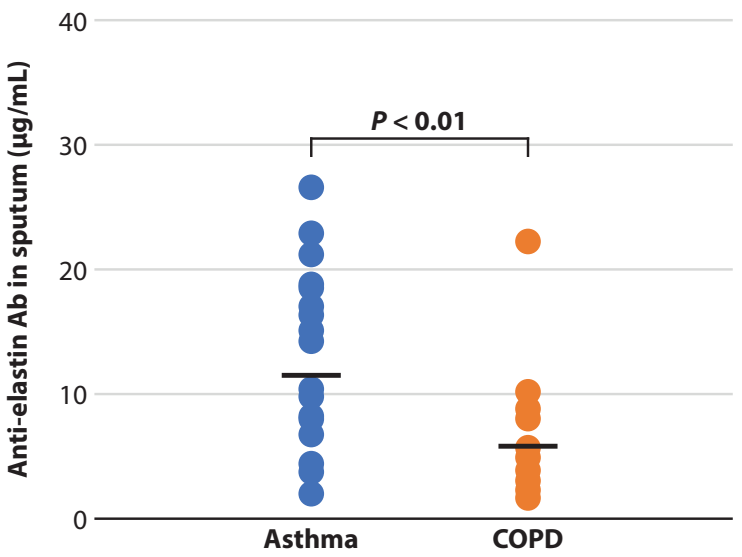

Results

Differences in anti-elastin Ab between asthma and COPD

The level of anti-elastin $\mathrm{Ab}$ in sputum was significantly higher in asthma than in COPD $(11.4 \pm 7.16 \mu \mathrm{g} / \mathrm{mL}$ vs 5.82 $\pm 5.16 \mu \mathrm{g} / \mathrm{mL}$, respectively; $P<0.01$; Figure $1 \mathbf{A})$. The level in serum was also significantly higher in asthma than in COPD or controls $(67.4 \pm 29.7 \mu \mathrm{g} / \mathrm{mL}$ vs $45.0 \pm 12.8 \mu \mathrm{g} / \mathrm{mL}, 38.6 \pm$ $10.4 \mu \mathrm{g} / \mathrm{mL}$, respectively; Figure 1B), and significant differences were observed between asthma and COPD $(P<0.05)$ and between asthma and controls $(P<0.01)$.

Relationship between cytology in sputum and anti-elastin Ab

The relationships between cytology and anti-elastin $\mathrm{Ab}$ in sputum are shown in Figure $\mathbf{2 A}$ and $\mathbf{B}$. In the evaluation of cytology by percentages, no significant correlations with the percentage of eosinophils were observed in either asthma or COPD (Figure 2A, $\mathrm{r}^{2}=0.012, \mathrm{r}^{2}=0.003$, respectively), and no significant correlations with the percentage of neutrophils were also observed in both asthma and COPD (Figure 2B, $\mathrm{r}^{2}=0.001, \mathrm{r}^{2}=0.005$, respectively). Anti-elastin Ab levels grouped by the number of eosinophils in sputum were not significantly different between asthma $(-=11.3 \pm 7.44$ $\mu \mathrm{g} / \mathrm{mL} ;+=10.8 \pm 9.25 \mu \mathrm{g} / \mathrm{mL} ;++=12.8 \pm 4.51 \mu \mathrm{g} / \mathrm{mL})$ and COPD $(-=5.85 \pm 5.47 \mu \mathrm{g} / \mathrm{mL}$; and $+=5.64 \pm 3.22 \mu \mathrm{g} / \mathrm{mL})$. Moreover, no significant differences in anti-elastin Ab levels grouped by the number of neutrophils in sputum were observed between asthma $(+=10.9 \pm 6.98 \mu \mathrm{g} / \mathrm{mL} ;++=11.7 \pm$ $7.50 \mu \mathrm{g} / \mathrm{mL})$ and COPD $(+=4.58 \pm 2.78 \mu \mathrm{g} / \mathrm{mL} ;++=6.31 \pm$ $6.24 \mu \mathrm{g} / \mathrm{mL}$; and $+++=5.90 \pm 4.09 \mu \mathrm{g} / \mathrm{mL})$.

The relationships between cytology in sputum and anti-elastin $\mathrm{Ab}$ in serum are shown in Figure 2C and D. In the evaluation of cytology by percentages, a significant correlation with the percentage of eosinophils was observed in COPD $\left(r^{2}=0.265, P<0.05\right)$, but not in asthma $\left(r^{2}=0.022\right)$ (Figure 2C). However, no significant differences in the percentage of neutrophils were observed in either asthma or COPD (Figure $2 \mathrm{D}, \mathrm{r}^{2}=0.011 \mathrm{r}^{2}=0.035$, respectively). Anti-elastin Ab levels grouped by the number of eosinophils were not significantly

\section{B}

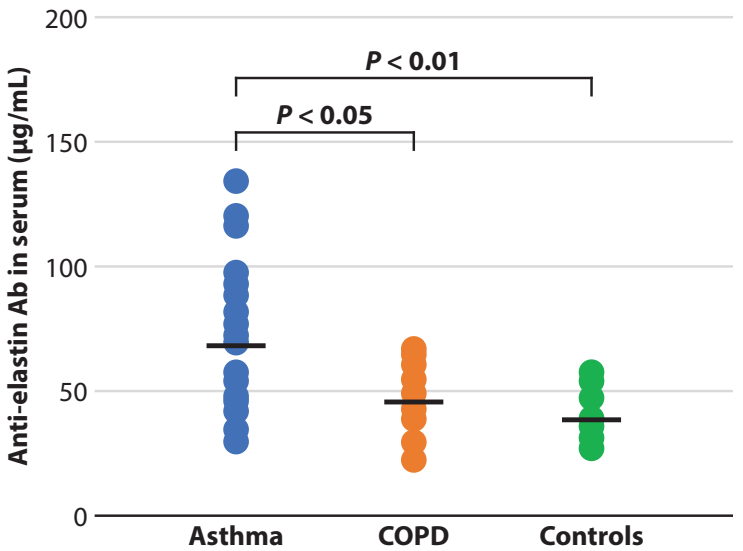

Figure 1. Anti-elastin Ab in asthma and COPD. The level of anti-elastin Ab in sputum (A) was significantly higher in asthma than in COPD $(P<0.01)$. Moreover, the level in serum $(B)$ was significantly higher in asthma than in COPD or controls $(P$ $<0.05, P<0.01$, respectively). 
A

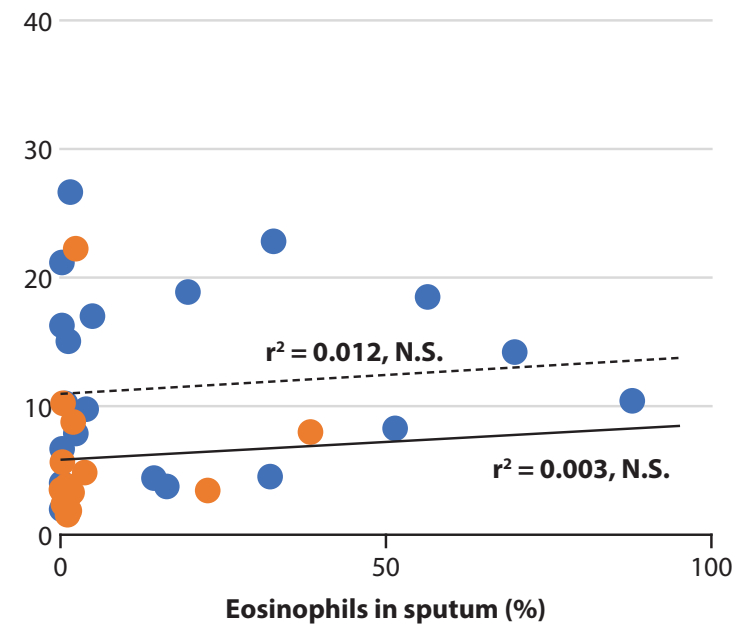

C

200

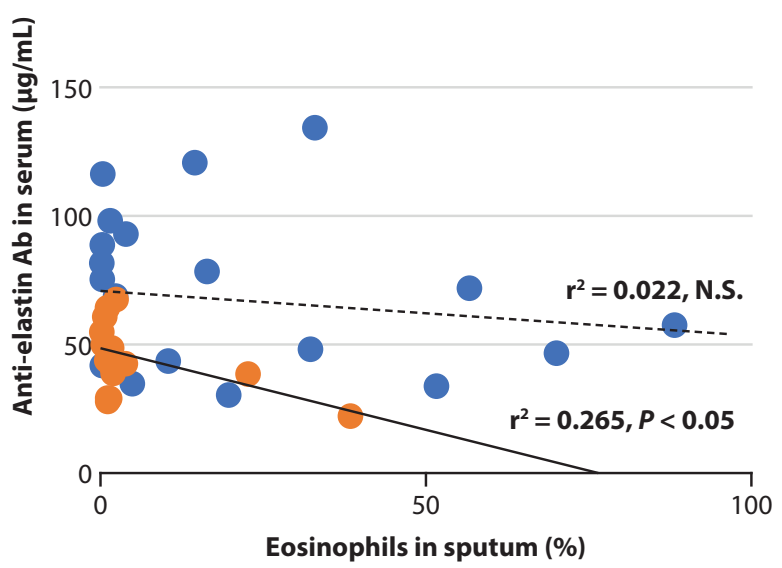

--- Asthma
B

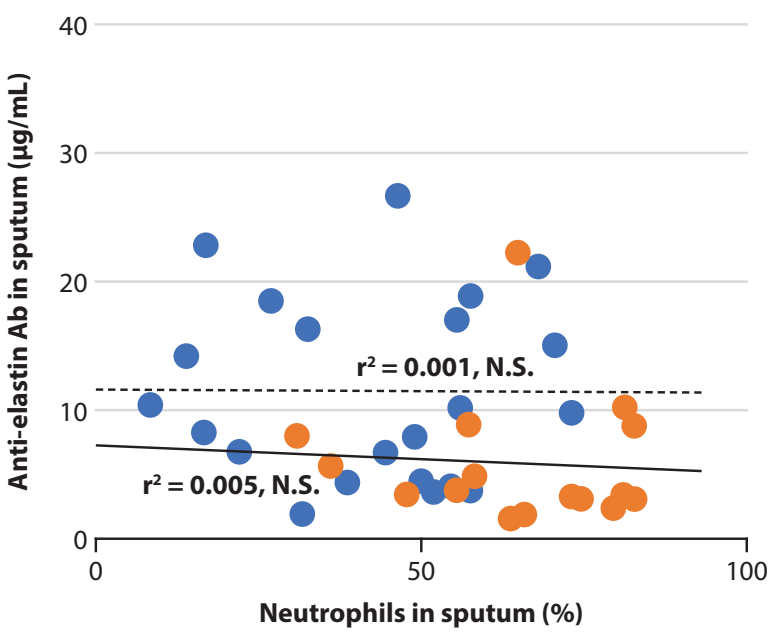

D

200

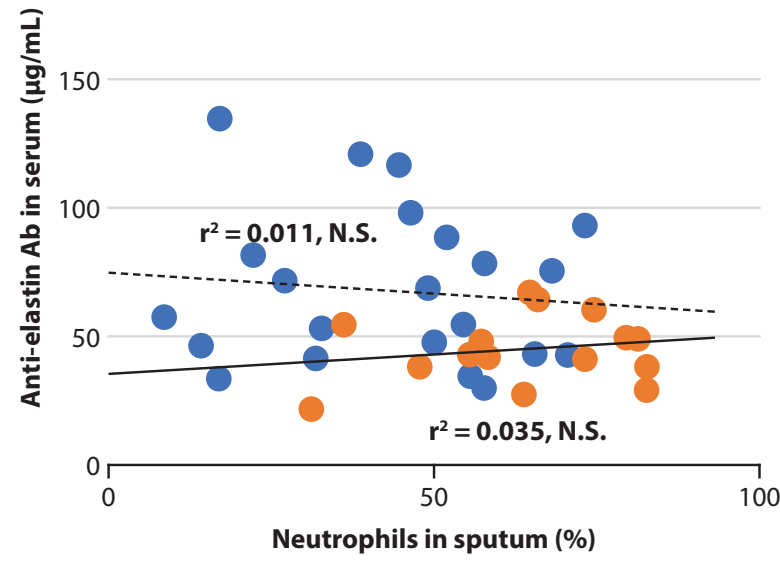

COPD

Figure 2. Relationships between cytology in sputum and anti-elastin $\mathrm{Ab}$ in sputum or serum. No significant correlations in the percentages of eosinophils (A) and neutrophils (B) in sputum were observed in either asthma or COPD. A significant negative correlation in the percentages of eosinophils in serum (C) was observed in COPD but not in asthma. However, no significant correlation in the percentages of neutrophils in serum (D) was observed in either asthma or COPD.

different between asthma $(-=68.4 \pm 25.7 \mu \mathrm{g} / \mathrm{mL} ;+=75.5 \pm$ $43.3 \mu \mathrm{g} / \mathrm{mL} ;++=52.1 \pm 16.2 \mu \mathrm{g} / \mathrm{mL})$ and COPD $(-=47.2$ $\pm 11.7 \mu \mathrm{g} / \mathrm{mL}$; and $+=29.9 \pm 11.5 \mu \mathrm{g} / \mathrm{mL}$ ). In addition, no significant differences in anti-elastin $\mathrm{Ab}$ levels grouped by the number of neutrophils were observed between asthma $(+=$ $70.3 \pm 38.0 \mu \mathrm{g} / \mathrm{mL} ;++=65.9 \pm 25.7 \mu \mathrm{g} / \mathrm{mL})$ and COPD $(+=$ $35.4 \pm 14.3 \mu \mathrm{g} / \mathrm{mL} ;++=47.0 \pm 11.5 \mu \mathrm{g} / \mathrm{mL}$; and $+++=54.0$ $\pm 8.57 \mu \mathrm{g} / \mathrm{mL})$.

\section{Relationship between patient background and anti-elastin $A b$}

A significant correlation between the Brinkman index (BI) and anti-elastin $\mathrm{Ab}$ in sputum was observed among patients with asthma $\left(r^{2}=0.218, P<0.05\right.$; Figure 3A). A weak correlation was also observed among patients with COPD, but not statistically significantly $\left(\mathrm{r}^{2}=0.260, P=0.052\right)$.
However, no significant correlation was observed between the $\mathrm{BI}$ and anti-elastin $\mathrm{Ab}$ in serum in patients with asthma, COPD, or controls $\left(r^{2}=0.100, r^{2}=0.033\right.$ and $r^{2}=0.093$, respectively; Figure 3B). Among patients with asthma, the level of anti-elastin $\mathrm{Ab}$ in sputum in ever-smokers and never-smokers was $13.4 \pm 7.22 \mu \mathrm{g} / \mathrm{mL}$ and $9.48 \pm 6.86 \mu \mathrm{g} / \mathrm{mL}$ (not significant [N.S.]), respectively. The level of anti-elastin $\mathrm{Ab}$ in serum in these two groups was $74.7 \pm 34.0 \mu \mathrm{g} / \mathrm{mL}$ and $60.7 \pm 24.7 \mu \mathrm{g} / \mathrm{mL}$ (N.S.), respectively. Among the controls, the level of anti-elastin $\mathrm{Ab}$ in serum in ever-smokers and in never-smokers was $37.7 \pm 10.5 \mu \mathrm{g} / \mathrm{mL}$ and $40.2 \pm 11.6 \mu \mathrm{g} / \mathrm{mL}$ (N.S.), respectively. There were no patients with COPD and non-smoking history. Among patients with ever-smokers, the levels of anti-elastin $\mathrm{Ab}$ in both sputum and serum were significantly higher in asthma than in COPD $(P<0.01$ and $P<$ 0.05 , respectively). 
A

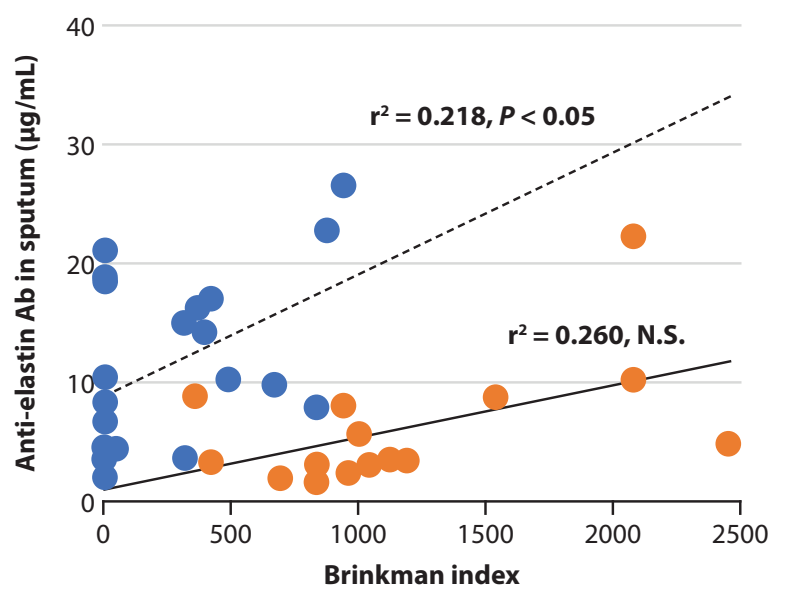

B

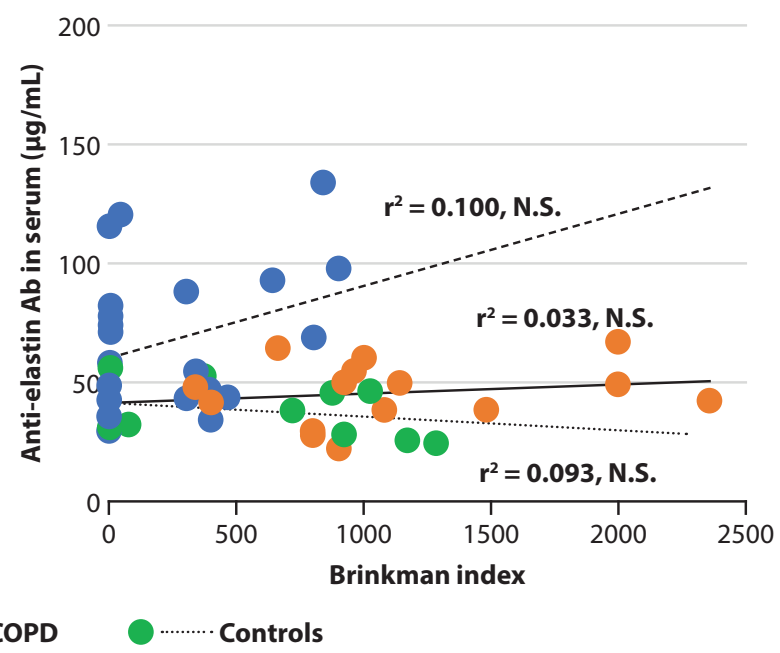

Figure 3. Relationships between the Brinkman Index in ever-smokers and anti-elastin Ab. A significant correlation between the Brinkman Index and anti-elastin $A b$ in sputum (A) was observed in patients with asthma $(P<0.05)$, but not in patients with COPD. However, no significant correlation between the Brinkman Index and anti-elastin Ab in serum (B) was observed in patients with either asthma or COPD.

Table 2. Levels of anti-elastin Ab according to severity, asthma phenotype, and comorbidity in patients with asthma.

\begin{tabular}{|c|c|c|}
\hline & Sputum & Serum \\
\hline \multicolumn{3}{|c|}{ Severity of asthma } \\
\hline Step 1 & $18.0 \pm 4.18$ & $76.7 \pm 50.0$ \\
\hline Step 2 & $10.2 \pm 7.72$ & $48.9 \pm 16.5$ \\
\hline Step 3 & $11.3 \pm 8.17$ & $67.3 \pm 30.2$ \\
\hline Step 4 & $8.93 \pm 5.47$ & $75.3 \pm 26.3$ \\
\hline \multicolumn{3}{|c|}{ Asthma phenotypes } \\
\hline Allergic & $9.40 \pm 5.11$ & $68.2 \pm 29.8$ \\
\hline Non-allergic & $13.0 \pm 8.55$ & $57.5 \pm 23.7$ \\
\hline Adult-onset & $11.4 \pm 7.16$ & $67.4 \pm 29.7$ \\
\hline Low $\% \mathrm{FEV}_{1}$ & $10.4 \pm 9.02$ & $79.0 \pm 30.0$ \\
\hline Obesity & $11.6 \pm 8.08$ & $72.3 \pm 19.2$ \\
\hline \multicolumn{3}{|c|}{ Comorbidities (with / without) } \\
\hline $\begin{array}{l}\text { Allergic } \\
\text { rhinitis }\end{array}$ & $8.42 \pm 6.29 / 13.2 \pm 7.26$ & $78.3 \pm 33.2 / 60.4 \pm 26.2$ \\
\hline Hypertension & $13.1 \pm 9.37 / 10.9 \pm 6.65$ & $69.2 \pm 21.9 / 66.8 \pm 32.6$ \\
\hline Diabetes & $18.4 \pm 6.22 / 9.37 \pm 6.14^{*}$ & $78.0 \pm 17.9 / 64.5 \pm 32.0$ \\
\hline Dyslipidemia & $18.9 \pm 4.43 / 8.62 \pm 5.86^{* *}$ & $60.1 \pm 22.2 / 70.6 \pm 32.6$ \\
\hline
\end{tabular}

Values are the mean \pm standard deviation $(\mu \mathrm{g} / \mathrm{mL}) ;{ }^{\star} P<0.05 ;{ }^{* *} P<0.01$ between with and without comorbidities.

No significant differences were observed between severities and between asthma phenotypes.

$\% \mathrm{FEV}_{1}$, forced expiratory volume in $1 \mathrm{~s}$ (\% of predicted)
No significant differences in anti-elastin $\mathrm{Ab}$ in sputum and serum were observed between the asthma phenotypes (Table 2). Given that asthma with persistent airflow limitation is typically severe, we also evaluated anti-elastin $\mathrm{Ab}$ in sputum and serum according to the severity of asthma in this group. However, no significant differences were observed between steps. In addition, we also analyzed the relationship between anti-elastin $\mathrm{Ab}$ and ICSs in patients with asthma. The correlations of dose of ICSs ( $\mu \mathrm{g} /$ day) with level of anti-elastin Ab in sputum and that in serum were $\mathrm{R}^{2}=0.067$ and $\mathrm{R}^{2}=0.003$, respectively, and were not significant.

In the analysis of comorbidities, significant differences were observed in patients with diabetes and dyslipidemia. Among patients with asthma, the level of anti-elastin $\mathrm{Ab}$ in sputum was significantly higher in those with diabetes and/or dyslipidemia than in those without $(P<0.05$ and $P<0.01$, respectively). However, among patients with $C O P D$, the level of anti-elastin $\mathrm{Ab}$ in sputum was significantly lower in those with diabetes than in those without $(2.39 \pm 0.89 \mu \mathrm{g} / \mathrm{mL}$ vs $6.97 \pm 5.51 \mu \mathrm{g} / \mathrm{mL}, P<0.05)$, and no significant differences were observed in patients with all other comorbidities. Among the controls, the level of anti-elastin $\mathrm{Ab}$ in serum was significantly higher in those with diabetes than in those without $(50.4 \pm 5.99 \mu \mathrm{g} / \mathrm{mL}$ vs $34.6 \pm 8.42 \mu \mathrm{g} / \mathrm{mL}, P<0.05)$, and no significant differences were observed in patients with other comorbidities.

\section{Location of elastin in human lung tissue}

The locations of elastin in human lung tissue are shown in Figure 4. Elastin was strongly expressed under the basement membrane around the airways in asthma (Figure 4A) compared with COPD (Figure 4B) and the healthy control (Figure $4 \mathrm{C}$ ). 

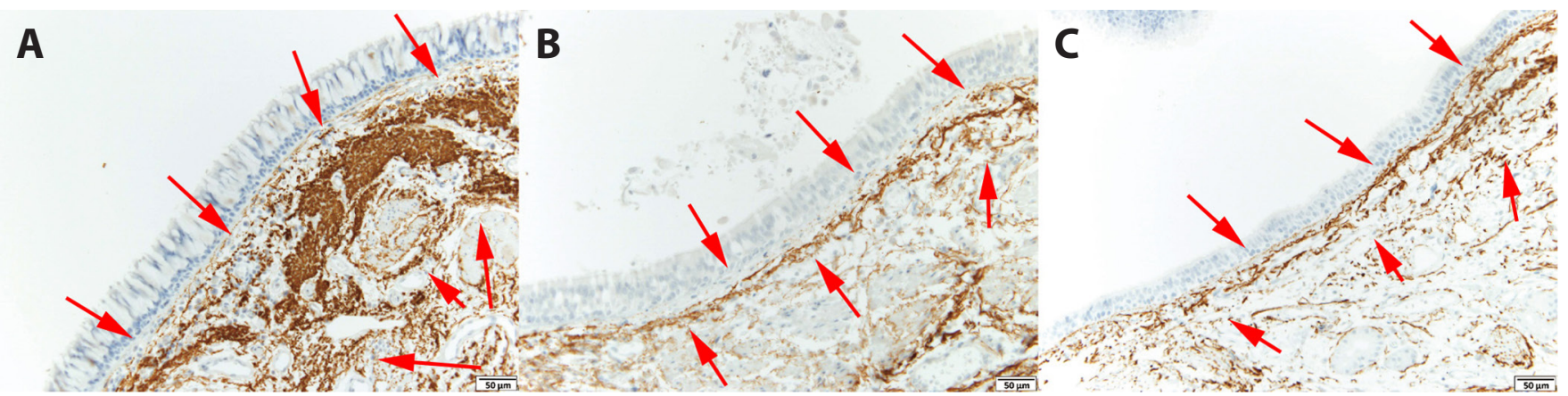

Figure 4. Locations of elastin in lung tissue. Elastin shown by a brown color was more strongly expressed under the basement membrane around the airways in asthma (A) than in COPD (B) or the healthy control (C).

\section{Discussion}

It has been hypothesized that COPD might be an autoimmune disease in which anti-elastin $\mathrm{Ab}$ is produced by smoking. and emphysema progresses via anti-elastin $\mathrm{Ab}$ even after quitting smoking., ${ }^{2,3}$ In a mouse model of COPD inoculated with extracellular matrix proteins, anti-elastin immunoglobulin M (IgM) was increased by smoking. ${ }^{9}$ However, other studies have reported that anti-elastin $\mathrm{Ab}$ is decreased by smoking and not increased in patients with COPD, ${ }^{5,10}$ which is consistent with our results. Thus, the relationship between COPD and anti-elastin Ab has not been clarified, and positive results may be found in asthma-COPD overlap, but not pure COPD. ${ }^{2,3}$ In patients with COPD, elastin is produced by the skin and is degraded more quickly than in normal controls. ${ }^{11}$ Elastin is also increased by sun exposure, and this increase correlates positively with the severity of COPD.

Regarding the relationship between anti-elastin $\mathrm{Ab}$ and other organs, elastin in serum has been found to be increased in patients with arteriosclerosis, ${ }^{12,13}$ and anti-elastin $\mathrm{Ab}$ has been shown to be increased in patients with symptomatic carotid stenosis. ${ }^{14}$ However, in other reports, anti-elastin $\mathrm{Ab}$ has been found to be lower in patients with arteriosclerosis and coronary artery disease. ${ }^{15,16}$ Moreover, anti-elastin Ab levels were found to be significantly higher in horses with moderate and severe arteriosclerosis than in healthy horses. ${ }^{17}$ Although the target organ of anti-elastin $\mathrm{Ab}$ is unknown in horses, it may be a biomarker of health status. In our study, significant differences were observed in diabetes and dyslipidemia, but the same results were not found between the asthma, COPD, and control groups. We were not able to find reasons for the observed effects of diabetes and dyslipidemia as systemic diseases on anti-elastin $\mathrm{Ab}$ in sputum but not in serum. We considered that smoking might have some effects, so we evaluated BI. Among patients with asthma, the BI score in patients with diabetes and in those without was $378 \pm 396$ and $196 \pm 282$, respectively. The respective scores were $900 \pm 212$ and $1204 \pm$ 670 in patients with COPD and $633 \pm 553$ and $503 \pm 528$ in controls. The level of anti-elastin Ab was higher in the groups with higher BI score, but no significant differences were observed according to diabetes status and BI. For dyslipidemia, almost the same results were observed. These results together with the findings of the abovementioned studies suggest that smoking has a greater effect on the production of anti-elastin $\mathrm{Ab}$ than arteriosclerosis.
In asthma, increased proliferation of elastic fibers in the airways contributes to hyperresponsiveness and residual obstruction in asthmatic airways. ${ }^{18,19}$ Exacerbation of asthma may contribute to the production of elastin because hypoxia increases elastin secretion from arterial smooth muscle cells. ${ }^{20}$ As shown in Figure 4, in the present study, elastin under the basement membrane around bronchi, which causes airway remodeling, was expressed more strongly in patients with asthma than in those with COPD or controls. The reasons for the increase in anti-elastin $\mathrm{Ab}$ in patients with asthma are not known, and we could not find any reports on a relationship between these factors. According to our results, eosinophils and neutrophils did not contribute to the production of anti-elastin Ab. Also, phenotypes, severity of asthma, and dose of inhaled corticosteroids did not contribute to the production of anti-elastin Ab. However, our analysis of asthma phenotypes was insufficient, because none of the patients we examined had childhood-onset asthma. Although smoking history may affect the production of anti-elastin $\mathrm{Ab}$, the mechanism by which smoking has an effect in only patients with asthma is not yet known. To gain an understanding of the targets of anti-elastin $\mathrm{Ab}$, we performed anti-elastin $\mathrm{Ab}$ staining of lung tissue; however, it was difficult to detect anti-elastin $\mathrm{Ab}$ in lung tissue. We considered that there are two contrary hypotheses regarding the role of anti-elastin $\mathrm{Ab}$. One is that it is produced to inhibit increases in elastin and airway remodeling, and the other is that it causes airway remodeling via severe inflammation with an antigen-antibody reaction to elastin under the basement membrane of bronchi. The role of anti-elastin $\mathrm{Ab}$ in this study was investigated using a mouse model of asthma. Anti-elastin $\mathrm{Ab}$ in bronchoalveolar lavage fluid is significantly increased in the mouse model of asthma.

One limitation of this study was that we did not evaluate sputum in a control group. We tried to collect sputum from controls without asthma and/or COPD via inhalation of physiological saline solution. However, the controls did not have respiratory symptoms, and the majority of samples collected were only saliva. Given that the levels in pure sputum could not be evaluated, we did not measure them in the controls and instead evaluated them in an animal model in another study. Another limitation was that we evaluated only a single histological specimen in each group. 


\section{Conclusion}

Anti-elastin $\mathrm{Ab}$ in both serum and sputum was significantly increased in patients with asthma. Smoking was found to contribute to the production of anti-elastin $\mathrm{Ab}$ in patients with asthma only, not in those with COPD or in controls. However, the role of anti-elastin $\mathrm{Ab}$ in asthma remains to be elucidated. Anti-elastin $\mathrm{Ab}$ could be a useful biomarker to differentiate between COPD and asthma in patients with smoking history.

\section{Acknowledgments}

We thank Mr. Kazunori Fukuda, Mr. Junichi Koyatsu, and Ms. Ayako Yamamoto of Dokkyo Medical University Saitama Medical Center for technical assistance. We also thank Ms. Seiko Sekiguchi of Dokkyo Medical University Saitama Medical Center for assistance preparing the manuscript.

\section{Conflict of interest}

The authors have no conflicts of interest to declare.

\section{Source of funding}

This study was supported by Dokkyo Medical University.

\section{Authors contributions}

- ST, KS, and YF contributed to the conception and design of the study, the acquisition of data, and data analysis and interpretation.

- HA, TW, NO, KS, TO, and KK contributed to the conception and design of the study, the acquisition of data, and interpretation of the data.

- YU contributed to the cytological evaluation.

- HH, MA, and KK contributed to the conception and design of the study and the interpretation of data.

- All authors read and approved the final manuscript.

\section{References}

1. Global initiative for chronic obstructive pulmonary disease [Internet]. Fontana: GOLD; c2021 [cited 2021 Jan 11]. Global strategy for the diagnosis, management, and prevention for chronic obstructive pulmonary disease (2018 report); [about 1 screen] Available from: https://goldcopd. org/wp-content/uploads/2017/11/GOLD-2018-v6.0-FINAL-revised -20-Nov_WMS.pdf.

2. Brusselle GG, Joos GF, Bracke KR. New insights into the immunology of chronic obstructive pulmonary disease. Lancet. 2011;378:1015-26.

3. Bonarius HP, Brandsma CA, Kerstjens HA, Koerts JA, Kerkhof M, Nizankowska-Mogilnicka E, et al. Antinuclear autoantibodies are more prevalent in COPD in association with low body mass index but not with smoking history. Thorax. 2011;66:101-7.
4. Lee SH, Goswami S, Grudo A, Song LZ, Bandi V, Goodnight-White S, et al. Antielastin autoimmunity in tobacco smoking-induced emphysema. Nat Med. 2007;13:567-9.

5. Wood AM, de Pablo P, Buckley CD, Ahmad A, Stockley RA. Smoke exposure as a determinant of autoantibody titre in a1-antitrypsin deficiency and COPD. Eur Respir J. 2011;37:32-8.

6. Global Initiative for Asthma [Internet]. Fontana: Global Initiative for Asthma; c2021 [cited 2021 Jan 11]. Global strategy for asthma management and prevention. Updated 2018; [about 1 screen]. Available from: https:// ginasthma.org/wp-content/uploads/2019/01/2018-GINA.pdf.

7. Global Initiative for Asthma [Internet]. Fontana: Global Initiative for Asthma; c2021 [cited 2021 Apr 13]. Global strategy for asthma management and prevention. Updated 2020; [about 1 screen]. Available from: https://ginasthma.org/wp-content/uploads/2020/06/GINA-2020 -report_20_06_04-1-wms.pdf.

8. Derendorf H, Meltzer EO. Molecular and clinical pharmacology of intranasal corticosteroids: clinical and therapeutic implications. Allergy. 2008;63:1292-300.

9. Brandsma CA, Timens W, Geerlings M, Jekel H, Postma DS, Hylkema $\mathrm{MN}$, et al. Induction of autoantibodies against lung matrix proteins and smoke-induced inflammation in mice. BMC Pulm Med. 2010;10:64.

10. Greene CM, Low TB, O’Neill SJ, McElvaney NG. Anti-proline-glycine -proline or antielastin autoantibodies are not evident in chronic inflammatory lung disease. Am J Respir Crit Care Med. 2010;181:31-5.

11. Maclay JD, McAllister DA, Rabinovich R, Haq I, Maxwell S, Hartland $\mathrm{S}$, et al. Systemic elastin degradation in chronic obstructive pulmonary disease. Thorax. 2012;67:606-12.

12. Fülöp T Jr, Wei SM, Robert L, Jacob MP. Determination of elastin peptides in normal and arteriosclerotic human sera by ELISA. Clin Physiol Biochem. 1990;8:273-82

13. Baydanoff S, Nicoloff G, Alexiev C. Age-related changes in the level of circulating elastin-derived peptides in serum from normal and atherosclerotic subjects. Atherosclerosis. 1987;66:163-8.

14. Tzvetanov P, Hegde V, Al-Hashel JY, Atanasova M, Sohal AP, Rousseff RT. Abnormal levels of serum anti-elastin antibodies in patients with symptomatic carotid stenosis. Clin Neurol Neurosurg. 2014;116:9-12.

15. Baydanoff S, Nicoloff G, Alexiev C. Age-related changes in anti-elastin antibodies in serum from normal and atherosclerotic subjects. Atherosclerosis. 1987;63:267-71.

16. Lee SH, Shin K, Park S, Kang SM, Choi D, Lee SH, et al. Circulating Anti-Elastin Antibody Levels and Arterial Disease Characteristics: Associations with Arterial Stiffness and Atherosclerosis. Yonsei Med J. 2015;56:1545-51.

17. De Keyser K, Berth M, Christensen N, Willaert S, Janssens S, Ducatelle R et al. Assessment of plasma anti-elastin antibodies for use as a diagnostic aid for chronic progressive lymphoedema in Belgian Draught Horses. Vet Immunol Immunopathol. 2015;163:16-22.

18. Ingram JL, Slade D, Church TD, Francisco D, Heck K, Sigmon RW, et al Role of Matrix Metalloproteinases-1 and -2 in Interleukin-13-Suppressed Elastin in Airway Fibroblasts in Asthma. Am J Respir Cell Mol Biol. 2016;54:41-50.

19. Setlakwe EL, Lemos KR, Lavoie-Lamoureux A, Duguay JD, Lavoie JP Airway collagen and elastic fiber content correlates with lung function in equine heaves. Am J Physiol Lung Cell Mol Physiol. 2014;307:L252-260.

20. Kawakami S, Minamisawa S. Oxygenation decreases elastin secretion from rat ductus arteriosus smooth muscle cells. Pediatr In. 2015;57:541-5. 